www.jmscr.igmpublication.org Impact Factor 5.244

Index Copernicus Value: 83.27 ISSN (e)-2347-176x ISSN (p) 2455-0450 crossref DOI: _https://dx.doi.org/10.18535/jmscr/v4i11.52

\author{
Journal Of Medical Science And Clinical Research

\title{
Upper GI Endoscopic Findings with Cholelithiasis
}

\author{
Authors \\ Dr K.C.M.Rajkumar ${ }^{1^{*}}$, Prof. Dr R.Ramesh ${ }^{2}$, Dr K. Ravichandran ${ }^{3}$ \\ ${ }^{*}$ Post Graduate, Department of Surgery, Raja Muthiah Medical College and Hospital, Annamalai \\ University, Chidambaram, Tamilnadu \\ ${ }^{2}$ Professor, Department of Surgery, Raja Muthiah Medical College and Hospital, Annamalai University, \\ Chidambaram, Tamilnadu \\ ${ }^{3}$ Reader, Department of Surgery, Raja Muthiah Medical College and Hospital, Annamalai University, \\ Chidambaram, Tamilnadu
}

\begin{abstract}
Background: Upper abdominal symptoms like abdominal pain, dyspepsia etc are most often attributed to bilary disease and many patients continue to complain the same symptoms after cholecystectomy. So upper GI Endoscopy performed for patients with Cholelithiasis before cholecystectomy to exclude upper GI pathology other than Cholelithiasis.

Aims: To Assess the valve of pre-operative upper GI endoscopy in patients with Cholelithiasis.

Patients and Methods: This is a Retrospective Hospital based study. Fifty Symptomatic adult patients diagnosed having cholelithiasis by ultrasound who underwent pre-operative oesophagoduodenoscopy were included in this study.

Results: OGD Revealed different pathological findings in 37 (74\%) out of 50 patients with GSD.

Conclusions: OGD cholelithiasis for detection of upper GI pathology Responsible for symptoms.

Keywords: Gallstone disease, upper Gastrointestinal Endoscopy Reflux esophagitis, gastritis, dyspepsia.
\end{abstract}

\section{Introduction}

Cholelithiasis is one of the most common and costly of all digestive diseases. Common causes of upper abdominal symptoms are peptic ulcer, acute and chronic gastritis and gallstones. However, in the earlier days the role of upper GI endoscopy before doing cholecystectomy was controversial $^{(2)}$. Several studies showed that patients with symptomatic gallstones and negative oesophago-gastroendenoscopy (OGD) remain asymptomatic after cholecystectomy, while patients with positive OGD findings contain symptomatic after cholecystectomy ${ }^{(3)}$. The coincidence of asymptomatic gallstones has been understood recently, largely due to application of ulstrosonographic scanning of people for other reasons. Many problems have been associated with cholelithiasis including old age, obesity, diabetes mellitus, alcoholism, smoking and estrogen replacement therapy ${ }^{(9)}$. The natural history of asymptomatic gallstones suggests that a large number of affected individuals remain asymptomatic for life; only $1-4 \%$ per year will develop symptoms or complications of gallstones. Only $10 \%$ will develop symptoms or complications of gallstones. Only $10 \%$ will develop symptoms in the first five years after diagnosis and 20\% 20 years after diagnosis. Almost all 
patients will experience symptoms for a period of time before they develop complications. None of the features, like number of stones, size, shape, nature, wall thickness, gallbladder contractility, patients gender or age, were found to be predictive of symptoms or complications like acute cholecystitis, obstructive jaundice, pancreatitis or gallbladder cancer ${ }^{(10)}$.

\section{Review of Literature}

Upper GI endoscopy was done to 1064 out of $1143(93.1 \%)$ patients with cholelithiasis before elective cholecystectomy. Upper GI pathological findings were detected in 345 patients $(30.2 \%)(4)$. In another study, upper GI pathology was detected in $31 \%$ of 100 patients with cholelithiasis before elective cholecystectomy, of whom 7 patients were excluded from cholecystectomy ${ }^{(5)}$.

Another study, OGD was performed in 338 patients before cholecystectomy. Pathological findings were detected in 160 (3\%); 6.8\% had peptic ulcer disease, $25.7 \%$ gastritis, oesophagitis, $4.7 \%$ hiatus hernia and $0.6 \%$ had gastric ulcer. Cholecystectomy was postponed in 23 patients with ulcers and 2 patients with gastric cancer underwent gastrectomy ${ }^{(6)}$.

A study conducted between 1993 and 2002, where 2800 patients were enrolled and upper GI endoscopy was done for patients with cholelithiasis before elective laparoscopic cholecystectomy. Preoperative endoscopy 1-4 days before operation showed pathologic changes in the stomach or duodenum in 1187 (42\%) patients; gastric ulcer was and in 179(6.4\%) duodenal ulcer in $127(4.2 \%)$ gastritis patients. Cholecystectomy was not done for patients with peptic ulcer and most of them became asymptomatic after antiulcer treatment ${ }^{(7)}$.

\section{Objectives}

To study the prevalence of dyspeptic symptoms in patients with Cholelithiasis. To study the age distribution of clinically significant lesions on upper GI endoscopy in patients with Cholelithiasis. To study the sex distribution of various pathologies in upper GI endoscopy in these patients.

\section{Patients and Methods}

This was Retrospective Hospital based study conducted at Raja Muthiah Medical College and Hospital during the period of Sep-2011 to Sep2016 (fifty patients were included). All patients underwent OGD after being diagnosed as having cholelithiasis proved by ultrasonographic scan.

The data has been collected from the MRD department at Raja Muthiah Medical College and Hospital.

\section{Results}

Fifty patients were included in this study. OGD was done for all patients in this study. $13(26 \%)$ had normal OGD findings while 37 (74\%) had different GI pathologies.

\begin{tabular}{|l|c|c|}
\hline $\begin{array}{l}\text { ENDOSCOPIC } \\
\text { FINDINGS }\end{array}$ & $\begin{array}{c}\text { NO. OF } \\
\text { SUBJECTS }\end{array}$ & PERCENTAGE \\
\hline Gastritis & 15 & $30 \%$ \\
\hline Duodenal Ulcer & 11 & $22 \%$ \\
\hline Hiatus Hernia & 10 & $20 \%$ \\
\hline Lower End Esophagitis & 1 & $2 \%$ \\
\hline Normal & 13 & $26 \%$ \\
\hline
\end{tabular}

\section{Discussion}

In this study, OGD was done for 50 adult patients with symptomatic gallstones to look for upper GI lesions other than gall stone disease. Regarding the abdominal signs in the study, most of the patients had right hypochondrial pain/ epigastric tenderness. Sonographic findings showed most of the patients had multiple gall stones. OGD findings were detected in 37 patients. 15 patients had Gastritis, 11 patients had Duodenal Ulcer, 10 patients had Hiatus Hernia. Review of literature shows OGD done for 376 patients with symptomatic gall stones. Only 60 patients showed gastroscopic findings where gastric erosion, peptic ulcer, oesophagitis were seen in 15, 14 and 11 patient respectively. ${ }^{(8)}$.

No complications attributed to OGD were seen in the study. OGD seems to be great value in diagnosing upper GI pathology in patients with 
GSD prior to Cholecystectomy and hence it is recommended as a routine investigation prior to Cholecystectomy.

\section{Reference}

1. Everhart JE, Khare M, Hill M, Maurer KR. Prevalence and ethnic differences in gallbladder disease in the United States. Gastroenterology 1999; 117:632-9.

2. Al-Azawi D, Rayis A, Hehir D J. Esophagogastroduodenoscopy prior laparoscopic cholecystectomy. Journal of Laparoendoscopic and Advanced Surgical Techniques 200; 16:593-597.

3. Niv Y, Fraser GM. Is there a need for diagnostic upper gastrointestinal endoscopybefore cholecystectomy?. Isr J Med Sci 1995;31:536-9.

4. Schwenk W, Bohm B, Badke A, Zarras K, Stock W. Preoperative es ophagogastroduodenoscopy before elective surgical therapy of symptomatic cholelithiasis. Leber Magen Darm 1992;22:225-9.

5. Diettrich H, Wundrich B, Kobe E, Noack S, Weber K. Gastroscopy before cholecystectomy. Gastroenterol J. 1990;50:173-4.

6. Thybusch A, Schaube H, Schweizer E, Gollnick D, Grimm H. Significant value and therapeutic implications of routine gastroscopy before cholecystectomy. J Chir (Paris) 1996;133:171-4.

7. Sosada K, Zurawinski W, Piecuch J, Stepien T, Makarska J. Gastroduodenoscopy: a routine examination of 2, 800 patients before laparoscopic cholecystectomy. Surg Endosc 2005; 19:1103-8.

8. Ure BM, Spangenberger W, Lefering R, Dietric A, Troidl H. Routine gastroscopy before laparoscopic cholecystectomy: evaluation of the technology in 376 patients. Z Gastroenterol 1992; 30:529-33.

9. Zubler J, Markowski G, Yale S, Graham R, Rosenthal TC. Natural history of asymptomatic gallstones in family practice office practices. Arch Fam Med. 1998; 7:230-3.

10. Meshikhes AW. Asymptomatic gallstones in the laparoscopic era. J R Coll Surg Edin. 2002; 14:742-748. 